Review

\title{
Electroanalytical and Spectrophotometric Methods for the Determination of Melatonin-a Review
}

\author{
Hussain Alessa ${ }^{1,}$, Jalal T. Althakafy ${ }^{1}$, Amr L. Saber ${ }^{1,2}$ \\ ${ }^{1}$ Department of Chemistry, Faculty of Applied Science, Umm Al-Qura University, Makkah, Saudi \\ Arabia \\ ${ }^{2}$ Chemistry Department, Faculty of Science, Zagazig University, 44519-Zagazig, Egypt \\ *E-mail: hhessa@uqu.edu.sa
}

doi: $10.20964 / 2020.08 .04$

Received: 9 April 2020 / Accepted: 27 May 2020 / Published: 10 July 2020

\begin{abstract}
Melatonin (MT), chemically N-acetyl-5-methoxytryptamine, was initially recognized in bovine pineal tissue and hence it has been represented exclusively as a hormone. The hormone can be used as a sleep aid for the treatment of some sleep disorders. However, MT is discovered in the earliest life forms and presented plants, bacteria, insects, fungi, and vertebrates as well as humans. MT possess various features that differentiate it from being a classical hormone, such as its direct, non-receptor-mediated free radical scavenging activity. Also, MT can be absorbed and consumed in foodstuffs such as wheat, vegetables, fruits, rice and herbal medicines. MT can also be classified as a vitamin. It seems likely that MT at first developed as an antioxidant, transformed to a vitamin in the food chain, and in multicellular organisms, where it is created, it has gained autacoid, paracoid and hormonal properties. This review concerns about different electroanalytical and spectrophotometric methods that have been used for the detection of melatonin, especially in the last three decades. It also illustrates the different electrodes materials and their modifications as they are the heart of sensors detection systems.
\end{abstract}

Keywords: Melatonin; Electroanalytical detection; Carbon-based electrodes; spectrophotometric detection.

\section{FULL TEXT}

(C) 2020 The Authors. Published by ESG (www.electrochemsci.org). This article is an open access article distributed under the terms and conditions of the Creative Commons Attribution license (http://creativecommons.org/licenses/by/4.0/). 